\title{
REINTERPRETACIÓN DE LA CONCEPCIÓN ARTÍSTICA Y LOS TIPOS ICONOGRÁFICOS PALEOCRISTIANOS, BIZANTINOS Y ROMÁNICOS EN LOS MOSAICOS DEL CENTRO ALETTI (ROMA): EL PROGRAMA ICONOGRÁFICO DE LA CAPILLA DEL COLEGIO MAYOR SAN PABLO (MADRID, OCTUBRE DE 2009)
}

\author{
POR \\ MARÍA RODRÍGUEZ VELASCO ${ }^{1}$ \\ Universidad CEU San Pablo
}

\section{RESUMEN}

La iconografía desarrollada en el ábside de la capilla del Colegio Mayor San Pablo es exponente de la obra del Centro Aletti, gran renovador del arte litúrgico actual. Su director, Marko Iván Rupnik, afirmando el valor del símbolo, reinterpreta las imágenes paleocristianas y medievales mediante el protagonismo del color y la materia como claves del lenguaje vanguardista. En esta capiIla, estudiada en relación con otras obras del taller, se revela la unidad entre el mosaico y la arquitectura que decora.

PALABRAS CLAVE: Centro Aletti; Marko Iván Rupnik; Colegio Mayor San Pablo; iconografía cristiana.

\section{REINTERPRETATION OF THE ARTISTIC CONCEPTION AND EARLY CHRISTIAN, BYZANTINE AND ROMANESQUE ICONOGRAPHIC TYPES IN MOSAICS OF ALETTI CENTER (ROMA): THE ICONOGRAPHIC PROGRAM OF ST PAUL'S COLLEGE CHAPEL (MADRID, OCTOBER 2009)}

\begin{abstract}
The iconography in the apse of St. Paul's College chapel is representative of the work of the Aletti Center, a great innovator of current liturgical art. Its director, Marko Iván Rupnik, highlighting the value of symbolism, reinterprets the early Christian and medieval images through the role of color and material, considering them key to avant-garde language. In this chapel, analyzed in relation to other works from the workshop, unity between mosaic and architecture is revealed.
\end{abstract}

KEY WORDS: Aletti Center; Marko Iván Rupnik; St. Paul's College Chapel; Christian Iconography

COMO CITAR ESTE ARTíCULO / CITATION: Rodríguez Velasco, M. 2017. "Reinterpretación de la concepción artística y los tipos iconográficos paleocristianos, bizantinos y románicos en los mosaicos del Centro Aletti (Roma): el programa iconográfico de la capilla del Colegio Mayor San Pablo (Madrid, octubre de 2009)». Hispania Sacra 69, 140: 755-764. doi: 10.3989/hs.2017.047

Recibido/Received 30-10-2015

Aceptado/Accepted $\quad$ 01-07-2016

Marko IVÁn RupNik y el Centro Ezio Aletti (Roma): LA RENOVACIÓN DEL ARTE SACRO ACTUAL

Cuando en 2009 se decide remodelar la capilla del Colegio Mayor San Pablo se encarga el proyecto decorativo a Marko Iván Rupnik, director del taller de arte espiritual del

1 mrodriguez.fhm@ceu.es / ORCID iD: http://orcid.org/0000-0001 $-5905-7755$
Centro Ezio Aletti (Roma). ${ }^{2}$ Esta institución, con origen en el

\footnotetext{
2 Marko Iván Rupnik es sacerdote jesuita, de origen esloveno (Zadlog, 1954), reconocido también por su importante labor como docente en la Universidad Pontificia Gregoriana de Roma y por sus muchas publicaciones teológicas. Entres sus últimas publicaciones destacan Vedo un ramo di mandorlo. Riflessioni sulla vita religiosa, en colaboración con Maria Campatelli (Roma: Lipa 2015) o El arte de la vida. Lo cotidiano en la belleza (Madrid: Maior 2013). Este autor revela que, al entrar en el noviciado de la Compañía de Jesús, en 1973, sintió
} 
año 1993, se concibe también como centro de investigación teológica, con el objetivo de aunar tradición oriental y occidental en los primeros siglos del cristianismo y en la actualidad, partiendo fundamentalmente de los escritos patrísticos y de la teología rusa de los siglos XIX y XX. Marko Iván Rupnik, director del Centro desde su fundación, propone en sus programas iconográficos la reinterpretación de tipologías y símbolos de las manifestaciones artísticas paleocristianas y medievales con el lenguaje formal de las vanguardias. En la formación de este autor confluye esta doble vía, ya que por un lado apreciamos su admiración por los signos y relieves de las catacumbas, o su profundo conocimiento de los iconos, y por otro su investigación académica se ha centrado en el arte contemporáneo, dedicando su tesis de licenciatura en Teología, en la Universidad Pontificia Gregoriana, a Kandinsky (Vassili Kandinsky como acercamiento a una lectura del significado teológico del arte moderno a la luz de la teología rusa) y la de doctorado a la relación entre la teología y el arte (El significado teológico misionero del arte en la ensayística de Viaceslav Ivanivic Ivanov). Su inquietud por expresar la espiritualidad en el arte le lleva a concluir sus estudios de Bellas Artes con una Tesis dedicada a Luigi Montanarini (1906-1998), quien también consideraba el arte como reflejo del alma.

Cuando Rupnik comienza su andadura artística lo hace como pintor, definiéndose ya como gran colorista, con una paleta fauvista de colores vivos y muy contrastados, aplicados con violentas pinceladas que parecen luchar contra el lienzo, evocando la estética del último Van Gogh, o de Matisse, autor que se convierte en constante referencia para la obra de Rupnik. En estas primeras pinturas domina la abstracción, si bien también advertimos la reinterpretación de símbolos paleocristianos, como el pez, o el progresivo acercamiento a los iconos, en la medida que la Trinidad de Rublev empieza a emerger entre las pinceladas. Cuando Rupnik recibe el encargo de dirigir el taller artístico del Centro Aletti, dedicado en esencia a la decoración de espacios litúrgicos, entiende que debe ofrecer un arte que responda a la objetividad de la liturgia, sin prestarse a interpretaciones personales y subjetivas. ${ }^{3}$ Por ello desde este momento se produce una "conversión» hacia la

la necesidad de expresar la intensidad de su vida interior a través de la pintura, comenzando así su andadura artística en la Academia de Bellas Artes de Roma, donde culmina sus estudios con una tesis dedicada al pintor italiano Luigi Montanarini (1906-1998). Sus investigaciones artísticas siempre van en paralelo a sus estudios de teología y filosofía, despertándose desde el principio su admiración por aquellos artistas que manifiestan el drama del hombre con la exaltación del color y la materia. De hecho, el fauvismo se convierte en referencia para sus primeras pinturas, trabajadas mediante pinceladas muy espesas, de gran dinamismo y rugosa textura, con una fuerza expresiva que escapa a cualquier concepción racionalista. Estas pinturas iniciales se presentaron en una exposición monográfica (Roma, 1979), con gran éxito de crítica, si bien esto no satisfizo plenamente a Rupnik, quien nunca olvida que sus manifestaciones artísticas nacen con vocación de servicio, para expresar las más profundas inquietudes del hombre y la respuesta de Dios. Esta certeza le mueve desde entonces a buscar el Rostro de los rostros, alejándose poco a poco del camino de la abstracción para revitalizar y afirmar la objetividad de la liturgia en los programas iconográficos que coordina desde la dirección del Centro Aletti. Rodríguez Velasco 2012: 1065-1066. Rodriguez Velasco 2013.

3 No obstante, el autor afirma en repetidas ocasiones que abstracción y figuración no son caminos excluyentes sino posibilidades de expresión paralelas en el arte contemporáneo. Govekar y Rupnik 2013: 55. expresión figurativa, sin renunciar al protagonismo del color, para responder a la definición del propio autor sobre el arte litúrgico como aquel «en el que muchos se encuentran y se reconocen ${ }^{4}{ }^{4}$ Rupnik se considera a su vez artista matérico, pues para él la materia tiene una dignidad propia y cada material una posibilidad expresiva diferenciada. Para afirmar a la vez color y materia, el artista decide recuperar la técnica del mosaico, volviendo su mirada a los grandes mosaicos romanos, paleocristianos y bizantinos, aunque ahora imprimiéndoles caracteres propios del lenguaje visual de las vanguardias.

Desde su primera obra, la decoración de la Capilla Redemptoris Mater en el Palacio Vaticano (1996-1999), Rupnik ya revela como sus fuentes de inspiración se remontan al arte paleocristiano, bizantino, románico y, en menor medida, al gótico, épocas con expresiones artísticas de marcado carácter conceptual y litúrgico. Al Centro Aletti no le interesa la ruptura con la tradición, sino la afirmación de ésta a través del lenguaje actual, rechazando meras copias del pasado vacías de significado para el hombre del siglo xxı. Fruto de este eclecticismo es un particular lenguaje artístico donde es esencial la concepción de símbolo como recurso que permite aunar realidad material e intelectual. En el símbolo se unen la tradición gráfica y la tradición literaria, necesarias para una comprensión íntegra y en profundidad de los proyectos de Rupnik, donde forma y contenido son inseparables. ${ }^{5}$ Además, los programas iconográficos del Centro Aletti son siempre unitarios, pues cada figura y escena únicamente se comprende plenamente en su relación con el conjunto, utilizando a menudo para ello el recurso prefigurativo. Este planteamiento, ya presente en el arte paleocristiano, bizantino y románico, responde en la modernidad a la propuesta estética de Soloviëv (18531900), para quien la belleza siempre está en consonancia con la unidad de conocimiento, o con la invitación del cardenal Spidlík a mirar la identificación de belleza y unidad en las tradiciones de griegos y rusos. ${ }^{6}$

La unidad se explicita también en el modo de trabajar del Centro Aletti, con artistas anónimos que trabajan como "una sola mano», de modo que es difícil precisar hasta donde llega la intervención del maestro y donde comienza la de sus colaboradores, al modo de lo que sucedía en los talleres medievales. Es lo que ellos denominan un trabajo coral, alejado de la afirmación individual o del subjetivismo que tantas veces domina en el arte actual. ${ }^{7}$

Todos los rasgos apuntados hasta el momento se observan en la capilla del Colegio Mayor San Pablo, donde lo primero que llama la atención en la remodelación del año 2009 son las modificaciones arquitectónicas, transformando la planta basilical de origen en una cruz griega que favorece la centralidad del altar y la mayor proximidad del fiel a los mosaicos del ábside.

4 Cfr. VV.AA. 2002: 182.

5 La unión de la dimensión material y la espiritual en el signo es explicada por el propio autor en Spidlík y Rupnik 2013: 196.

6 Spidlík 2004: 144.

7 Rupnik 2009a: 70. 
LA REINTERPRETACIÓN DE TIPOS ICONOGRÁFICOS PALEOCRISTIANOS EN EL ALTAR del Colegio Mayor SAN PABlo

Una primera vista de la capilla concentra toda la atención en la riqueza cromática del testero (Figura 1$)^{8}$, mientras que el altar pudiera pasar desapercibido en el conjunto por su mayor sobriedad. Sin embargo, en sus cuatro caras, con gran simplicidad compositiva, se recortan motivos que afirman plásticamente el sentido litúrgico de esta pieza, trabajada como "piedra angular», con un repertorio decorativo que no es ajeno a la función y finalidad de la arquitectura y, más concretamente del altar. Al rodear la pieza contemplamos en sus cuatro lados figuras aisladas (panes, peces, serpiente y pelícano), reinterpretando todas ellas las imágenessigno que a partir del siglo III emergen, incisas en piedra o pintadas, en los loculi y arcosolia de las catacumbas ${ }^{9}$, afirmando la identidad cristiana de estos enterramientos.

FIGURA 1

Ábside de la Capilla del Colegio Mayor San Pablo (Fotografía: David Monreal)

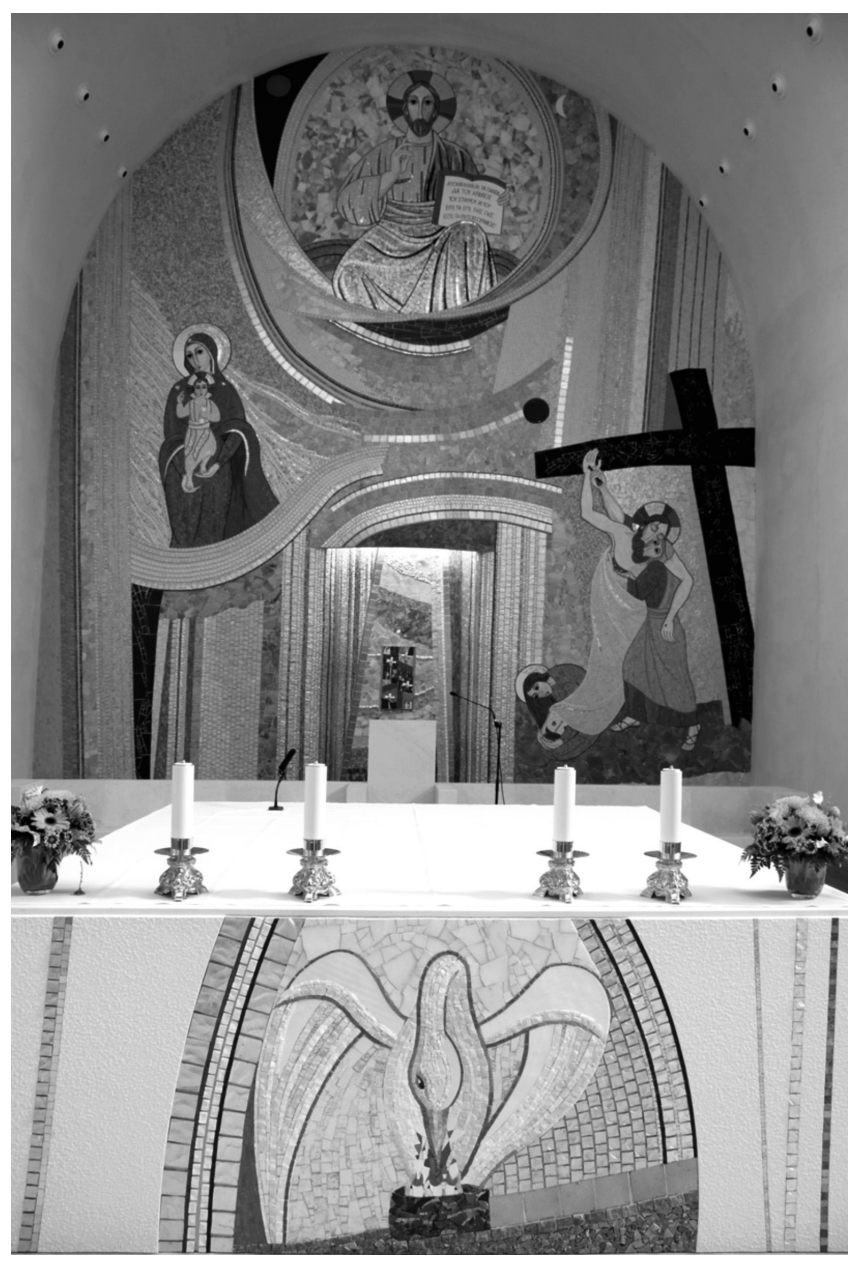

8 Agradezco a D. David Monreal, profesor de Fotografía de la Universidad CEU San Pablo, la cesión de todas las imágenes contenidas en el artículo.

9 Los arcosolia son enterramientos de mayor relevancia, rematados por un arco superior y generalmente decorados por pinturas. Los loculi son los enterramientos más sencillos de las primeras comunidades cristianas, nichos superpuestos en altura en los laberínticos pasillos de las catacumbas. Krautheimer 1981: 34.
Testimonios de las primeras comunidades atestiguan que estos mismos símbolos signaban también los sellos y objetos cotidianos que identificaban a los primeros cristianos entre sus coetáneos. ${ }^{10}$ De hecho, se conservan anillos del siglo IV con un repertorio de figuras que podría explicarse desde un fragmento del Pedagogo de Clemente de Alejandría (h. 150- h. 215): «Nuestros sellos deben llevar la imagen de una paloma, de un pez, de un navío a pleno viento, de una lira o de un ancla que Seleuco hizo grabar en su anillo. Si está figurado en ellos un pescador, esto debe recordarnos a los apóstoles.... ${ }^{11}$

Rupnik enriquece notablemente el tratamiento formal de los motivos, mediante el uso vanguardista del color y la materia como protagonistas, jugando con gran variedad de materiales, desde las teselas doradas que recuerdan el carácter sacro de las imágenes, hasta los cantos rodados del río, que hacen presente la cotidianidad de los signos. Pero lo que verdaderamente le lleva a recuperar estas figuras en la actualidad es su riqueza de significados, que requiere el conocimiento de los escritos patrísticos que las inspiraron en su origen y de los textos de la teología rusa contemporánea que reinterpretan las lecturas iniciales.

Volviendo al altar del Colegio Mayor, comencemos a examinar sus figuras. En uno de sus laterales se disponen dos sencillos peces (Figura 2), motivo presente en las imágenes de las catacumbas anteriores al año 313 para referir simbólicamente la figura de Cristo. El arte se hace eco de la literatura, que desde el siglo II había interpretado el término griego icthus, que significa pez, como acróstico de «Jesús Cristo de Dios Hijo Salvador». Ciertas inscripciones avalan esta analogía, como el epitafio de Abercio, datado en el siglo II, que señalaba que «en todas partes me sirvió como alimento un Pez de fuente, muy grande, muy puro, pescado por una santa Virgen y regalado a los amigos».12 Pero es a partir del siglo IV cuando los textos introducen con mayor frecuencia la relación entre el pez y la Eucaristía, parangón determinante para comprender su presencia en la decoración de este altar. San Agustín, fundiendo ambas interpretaciones, nos presenta a Cristo como pez del que la humanidad disfruta en la mesa, idea retomada en el siglo v por Pedro Crisólogo al apuntar en un sermón que "Cristo era el pez sacado del lecho del Jordán» y que "tras su resurrección ofreció un alimento vivificante a los suyos». ${ }^{13}$

Estos comentarios resultan familiares para Rupnik, por su conocimiento de los textos de la tradición, y por su gusto de visitar con frecuencia las catacumbas de Roma, donde le interpela particularmente el pez, un elemento cotidiano para los pescadores hebreos y también para el propio Cristo. ${ }^{14}$ La inquietud personal por dicho motivo quedó ya reflejada en la década de los ochenta del siglo xx en una serie pictórica dedicada a este motivo y titulada $I c t h u s^{15}$, término que remite de forma directa a la tradición paleocristiana. La bicromía se impone en esta serie, dominada por el azul y el rojo, dos colores esenciales para Rupnik como «fundamento
10 V.V.A.A. 2012: 116.

11 Cfr. Plazaola 1996: 21.

12 Ibídem: 40.

13 Cfr. Dölger 2013: 203-204.

14 Rupnik 2003: 80.

15 Sobre sus pinturas iniciales, Arriola Jiménez 2013. 
FIGURA 2

Peces (detalle lateral del altar de la capilla del Colegio Mayor San Pablo). (Fotografía: David Monreal)

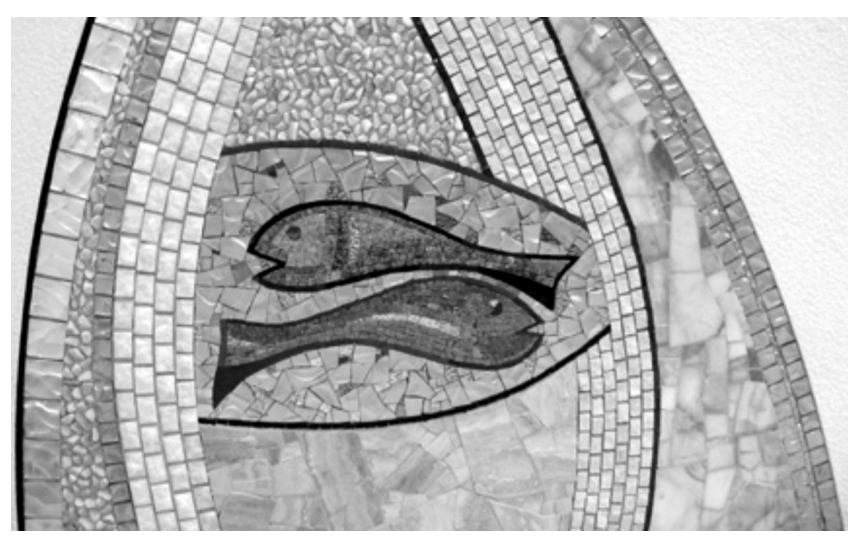

indestructible de la armonía de los colores». ${ }^{16}$ En su reflexión sobre los colores, el autor recuerda que "los cristianos del primer milenio ya reconocían en el rojo lo divino y en el azul lo humano ${ }^{17}$, por lo que ambos expresarían la doble naturaleza divina y humana de Cristo al ser empleados en las teselas que componen los peces en el altar de Madrid, si bien en este caso se recortan sobre un fondo dorado que exalta la trascendencia del motivo.

El significado eucarístico del pez explica que, a partir del siglo IV, en las pinturas de las catacumbas, se acompañe de un cesto de panes, como se observa en los frescos de la cripta de Lucina, en la catacumba de San Calixto. ${ }^{18}$ De esta forma se remite al mismo tiempo a la Eucaristía y a la narración bíblica de la multiplicación de los panes y los peces. También en la cara opuesta del altar del Colegio Mayor encontramos cinco panes sobre un cesto (Figura 3), haciendo explícito dicho milagro, no desde una perspectiva narrativa sino en su valor alegórico respecto a la Eucaristía. El número cinco, unido a los dos peces anteriores, obedece a los relatos de

FIGURA 3

Panes (detalle lateral del altar de la capilla del Colegio Mayor San Pablo). (Fotografía: David Monreal)

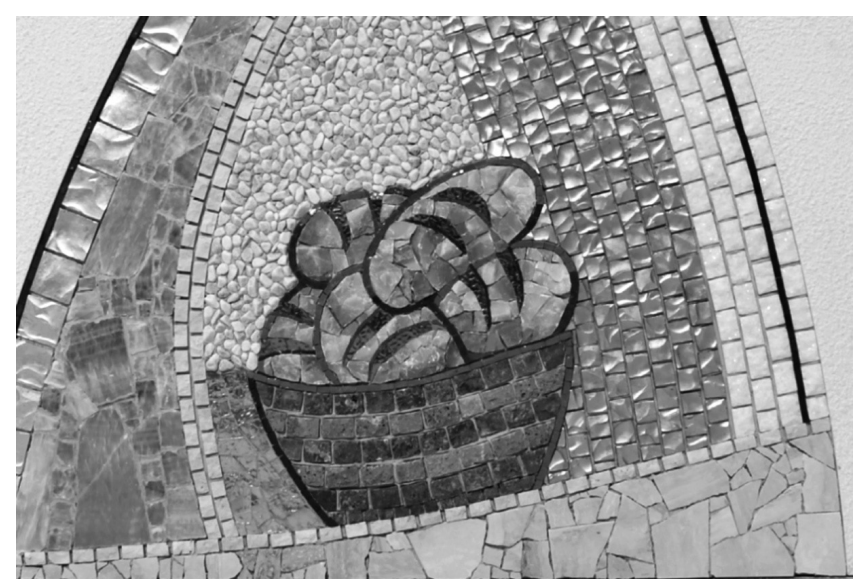

16 Cfr. Rupnik 2003: 70 .

17 Ibídem: 70.

18 Como figura independiente destaca su esquematismo en el Epitafio de Antonia, en las Catacumbas de Domitila. Mancinelli 1981: 27 y 1. los evangelistas, que precisan que los apóstoles únicamente contaban con «cinco panes y dos peces» para alimentar a la multitud que les había seguido. La exaltación de la materia propia de las obras de Rupnik se hace evidente al mezclar en esta representación la rudeza de cantos rodados de río con el brillo de las teselas blancas y doradas.

Si proseguimos rodeando el altar del Colegio Mayor, en la cara más próxima al oficiante se dispone la serpiente de bronce (Figura 4), motivo propio de la iconografía del patriarca Moisés, inspirado en el capítulo veintiuno del libro de los Números. La presencia de este animal en las imágenes implica una cierta ambivalencia, como recuerda también la literatura de Orígenes de Alejandría, pues por un lado se manifiesta su carácter nocivo ( El Señor envió entonces contra el pueblo serpientes muy venenosas que los mordían.

FIGURA 4

Serpiente (detalle del reverso del altar de la capilla del Colegio Mayor San Pablo). (Fotografía: David Monreal)

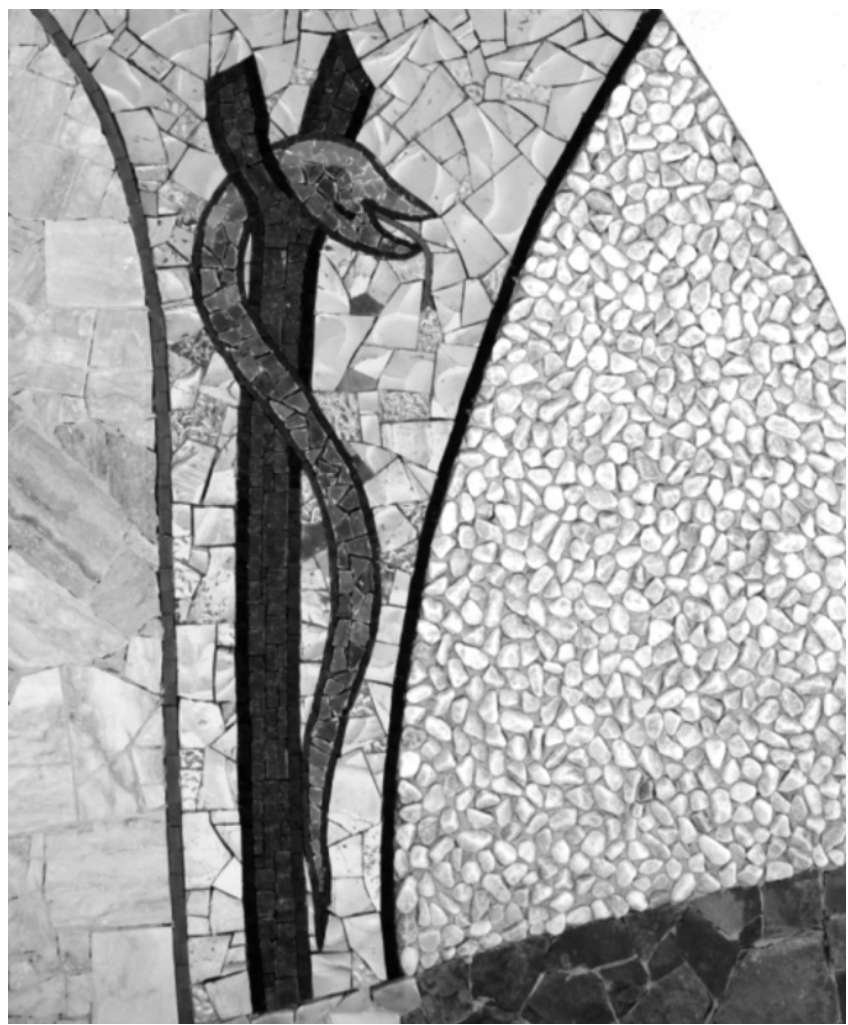

Murió mucha gente de Israel...», Nm 21, 6) y por otro su valor sanador, ya que en la antigüedad su veneno era utilizado como antídoto medicinal. Es este último significado el que prevalece en la interpretación de este altar, partiendo de la serpiente de bronce fundida por Moisés y colocada en un asta, como le había ordenado el Señor, para sanación de su pueblo ( "Hazte una serpiente de bronce, ponla en un asta, y todos los que hayan sido mordidos y la miren quedarán curados", Nm 21, 8). Al utilizar la serpiente Rupnik evoca también exégesis patrísticas, como la de san Ignacio de Antioquía, quien en Ad Ephesios definía la Eucaristía como «antídoto para no morir» o «medicina de inmortalidad». ${ }^{19}$

19 Dölger 2013: 210. 
Al disponer la serpiente sobre una cruz en forma de "tau», el autor recuerda la relación prefigurativa entre la serpiente de bronce fabricada por Moisés y la propia cruz, analogía presente en el evangelio de san Juan («Lo mismo que Moisés levantó la serpiente de bronce en el desierto, el Hijo del hombre tiene que ser levantado en alto, para que todo el que crea en Él tenga vida eterna», Jn 3, 14-15). ${ }^{20}$ En el programa decorativo de este altar no es casualidad que la serpiente se disponga en la parte del altar presidida por el sacerdote, pues también éste durante la consagración alzará el cuerpo de Cristo invitando a los fieles a su contemplación. De esta forma se hace presente una vez más la estrecha relación entre las imágenes y la liturgia, determinante en el arte paleocristiano y medieval.

Cerrando el recorrido por sus cuatro caras, en el anverso del altar, contemplamos el pelícano (Figura 1), que sintetiza, con mayor monumentalidad, de manera expresiva y directa, el significado eucarístico de toda la ornamentación. Para interpretar esta figura en el contexto litúrgico es preciso remontarnos al siglo II, cuando se data la versión griega del Physiologus, posteriormente traducido al armenio y al latín, que incluye la descripción de las especies animales, con una mezcla de realidad y fantasía que llegaría a tener un valor moralizante en relación a los vicios y las virtudes. ${ }^{21}$ Entre los animales ejemplares se encuentra el pelícano, ave que alimenta a sus polluelos con su propia sangre picoteándose el pecho, tal como se representa en este altar. Por entregar su propia vida por sus crías, los Bestiarios medievales, copiados y miniados en los scriptoria monásticos, presentaban al pelícano como alegoría de Cristo entregando su vida para la redención de los hombres. San Isidoro de Sevilla en sus Etimologías insiste en este simbolismo, señalando que el pelícano «merced a su sangre es capaz de resucitar a los polluelos».22 Estas lecturas llevaron a la doble interpretación del pelícano como símbolo cristológico y eucarístico, dado que el sacrificio de Cristo, que también entrega su sangre, es renovado durante la celebración de la Eucaristía. ${ }^{23}$

Como precedente de esta imagen entre los mosaicos del Centro Aletti encontramos la recreación del pelícano en la capilla de las Hermanas de la Caridad, en Fiume (Croacia, octubre de 2008). Respecto a la incidencia del altar madrileño en obras posteriores dirigidas por Rupnik, observamos prácticamente una réplica en el altar trabajado para la capilla de la Fraternidad de San Carlos Borromeo (Roma, diciembre 2010), donde el pelícano también se acompaña de los peces, panes y la serpiente de bronce, de nuevo en el reverso ${ }^{24}$, de modo que la diferencia entre ambos altares es básicamente estructural, obedeciendo a las dimensiones de las capillas. Al explicar este último conjunto romano, Rupnik señala que el pelícano, también en la cara principal del altar, implica la idea de la muerte pero también el significado pascual de la resurrección. ${ }^{25}$

En el altar del Colegio Mayor se pone de manifiesto la unidad de programas decorativos propia del Centro Ezio

\footnotetext{
20 Dulaey 2003: 269.
}

21 Sobre la relevancia, traducción a diversas lenguas y difusión del Physiologus en la Edad Media, Mâle 2001: 58-59.

22 Cfr. Malaxecheverría 1991: 222.

23 Sánchez López 1991.

24 Lynch 2011.

25 Rupnik 2011.
Aletti, a la vez que se introduce otro aspecto clave en la configuración de sus conjuntos: el valor de los espacios vacíos, con una consideración semejante a la de las propias figuras. En las cuatro caras del altar se omite cualquier escenografía que pueda desviar la atención del espectador. De este modo cobra protagonismo la variedad de materiales, cuya disposición dirige nuestra mirada a los motivos representados. Los espacios vacíos interpelan al espectador respecto al significado de las imágenes-signo paleocristianas en una pieza del siglo xxı. Sirvan para explicarlo las palabras del propio Rupnik: «... los espacios entre las figuras se deben cuidar con igual atención y fuerza creativa que las mismas figuras. Las figuras son como las palabras, como los discursos. La tarea de los espacios entre sí es entonces crear ese estado necesario en el corazón para que seamos capaces de acoger las palabras». ${ }^{26} \mathrm{Y}$ ante los interrogantes que surgen al "acoger» los distintos motivos el propio Rupnik nos ofrece respuesta, al afirmar que «el símbolo es un lenguaje privilegiado para el conocimiento», en la medida que "es una realidad por medio de la cual se comunica un concepto espiritual, transtemporal, metahistórico, pero a través del mundo histórico, temporal y tan concreto que hasta es palpable». ${ }^{27}$

\section{HERENCIA BIZANTINA EN EL TIPO ICONOGRÁFICO DEL PANTOCRÁTOR}

Mientras que en altar observamos la pervivencia del simbolismo paleocristiano en el arte sacro actual, en el testero de la capilla se hace presente la reinterpretación de modelos bizantinos a partir de la presencia del Pantocrátor, figura que preside el conjunto (Figura 5). También en su disposición se puede trazar una analogía con la distribución de los programas iconográficos en las iglesias bizantinas, donde la representación apocalíptica de Dios como Todopoderoso está prescrita para el ábside o para la cúpula, afianzando de este modo la jerarquización de la arquitectura. ${ }^{28}$ Desde sus primeras representaciones se definen la actitud, el gesto y los atributos iconográficos que se convierten en una constante para caracterizar al Pantocrátor: entronizado, bendiciendo y portando el libro de la vida. Además, su autoridad se refuerza plásticamente con el nimbo crucífero y el clípeo que enmarca la figura a modo de medallón, constituyendo una "imago clipeata», signo de la especial dignidad del personaje. ${ }^{29}$ También la dureza de sus rasgos, la frontalidad y el marcado hieratismo del rostro obedecen a la tradición bizantina, si bien Rupnik introduce detalles propios de su personal reinterpretación. ${ }^{30}$

\footnotetext{
26 Rupnik 2003: 205.

27 Rupnik 2000: 185-186.

28 Grabar 2007: 100.

29 En su evolución románica esta estructura se configura con un perfil almendrado conformando la mandorla. Respecto a la especial dignidad de la imago clipeata, Belting 2009: 147.

30 Ya en su primera intervención en la Capilla Redemptoris Mater los artistas del Centro Aletti incluyen la representación del Pantocrátor, figura que adquiere mayor monumentalidad en sus programas posteriores: San Pascual de Bari (abril de 2005); Parroquia de Ravoledo (Italia, diciembre de 2007); Cripta inferior de San Pietro de Pietrelciana (junio de 2009); Iglesia de Santa Elena (Eslovenia, noviembre de 2009); Iglesia de Todos los Santos (Eslovenia, diciembre de 2009); Capilla del Colegio Pontificio Irlandés (Roma, febrero de 2010); Iglesia de San Lorenzo
} (Roma, agosto de 2012). 


\section{FIGURA 5}

Pantocrátor (detalle del ábside de la capilla del Colegio Mayor San Pablo). (Fotografía: David Monreal)

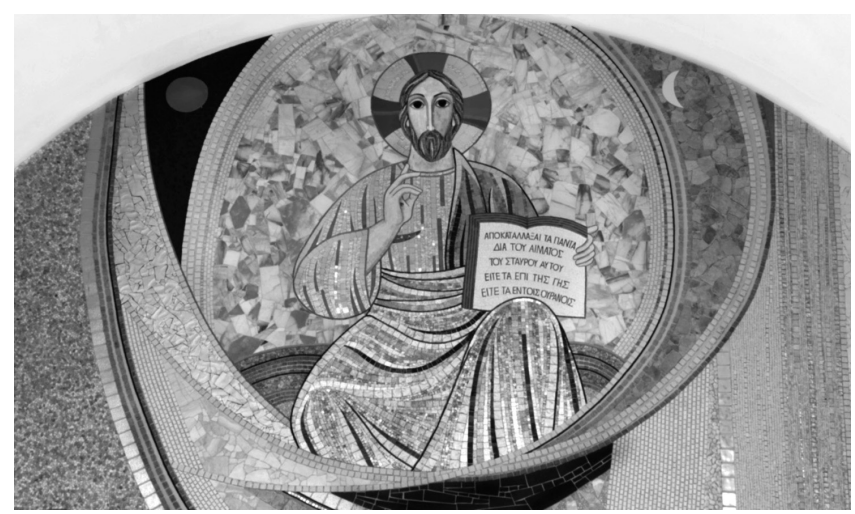

La primera novedad es la presencia de las llagas de la pasión, que nos recuerdan que para llegar a la Gloria, Cristo ha pasado previamente por el sacrificio de la cruz. Si observamos los mosaicos del Centro Aletti, con mucha frecuencia se opta por la anacrónica representación en las escenas de Cristo resucitado con los estigmas de la pasión. El segundo aspecto distintivo del Pantocrátor de Rupnik respecto a sus precedentes lo encontramos en el libro, atributo habitual para esta tipología en la tradición medieval, donde generalmente se completaba con las letras alfa y omega o con la inscripción «ego sum lux mundi». Sin embargo es aquí donde Rupnik innova, ofreciéndonos un texto que tiene relación directa con la advocación paulina del colegio mayor y de la capilla en particular. Su lectura nos lleva a un versículo tomado de la Epístola de san Pablo a los Colosenses: «con su sangre derramada en la cruz reconcilió en sí todas las cosas del cielo y de la tierra» (Col 1, 20). Esta afirmación sirve a su vez para sintetizar el programa iconográfico y reforzar su unidad, ya que refiere indirectamente las dos escenas inferiores, la Virgen de la Escala y el Descendimiento. El valor de la inscripción del libro en relación al conjunto se repite a menudo en los mosaicos del Centro Aletti cuando se trabaja al Pantocrátor, ya que, a excepción de las dos primeras versiones, donde el libro permanece cerrado y signado con la cruz, a partir de la intervención en San Giovanni Rotondo (2009) se convierte en soporte de inscripciones que recuerdan la advocación de una arquitectura, su función y finalidad o el carisma que la impulsa. ${ }^{31}$

Respecto a repertorios anteriores del Centro Aletti, el Pantocrátor de la capilla del Colegio Mayor está flanqueado por el sol y la luna, figuras que desde el mundo romano referían la idea de eternidad y cuyo simbolismo será ampliamente tratado por los escritos patrísticos. ${ }^{32}$ Las consideraciones de San Zenón de Verona, haciendo referencia a «Cristo como sol que no conoce ocaso después de

31 En la cripta de San Pio de Pietrelcina se dispone la inscripción "Yo soy la Vida»; en la iglesia de Todos los Santos (Ljubljana, Eslovenia) podemos leer, en consonancia con el programa iconográfico, «La caridad no tendrá nunca fin»; en el ábside del Colegio Pontificio Irlandés, en relación al edificio que decora, "Yo soy el Buen Pastor».

32 Dölger 2013: 59. Señala como la numismática de época de los emperadores Tito, Domiciano, Trajano y Adriano, mostraba a la Eternidad personificada por una figura femenina vestida sostenida por el sol y la luna. su Resurrección ${ }^{33}$, cobran actualidad en esta capilla por el valor dado a la luz a través del lampadario dispuesto sobre el altar, al que posteriormente nos referiremos. De esta forma Cristo es presentado también como Cosmocrator, Señor del cosmos, y como Cronocrátor, Señor del tiempo. Su figura se ve a su vez exaltada por una rica policromía, no exenta de significado, pues al dorado propio de la divinidad se suman el azul y el rojo, colores prioritarios en la paleta de Rupnik, que manifiestan respectivamente la doble naturaleza divina y humana de Cristo. ${ }^{34}$ Estos colores cobran mayor brillo en contraste con el negro, en la parte inferior de la figura, para insistir en su triunfo sobre la muerte. A su vez esta policromía está perfectamente equilibrada en el conjunto, encontrando su correspondencia en las escenas inferiores, para reforzar el sentido unitario del conjunto.

\section{SíMBOLOS Y SIGNIFICADO DE LA VIRGEN DE LA ESCALA EN UN} CONJUNTO ICONOGRÁFICO PAULINO

El dinamismo de líneas que parten del Pantocrátor conduce nuestra mirada hasta la figura de la Virgen con el Niño (Figura 6). Aunque a primera vista su frontalidad, sus rasgos y su presentación como trono de la divinidad remiten a la tipología de la Theotokos bizantina, Rupnik reinterpreta este modelo a partir de los gestos. Así, la posición en distintos niveles de los pies de Cristo y de las manos de la Virgen, simulando peldaños ascendentes y descendentes, le lleva a crear la Virgen de la Escala. ${ }^{35}$ De esta forma, se muestra a Cristo ascendiendo hacia el Pantocrátor, recordando que es continuamente generado por el Padre, y a la vez descendiendo, entrando en el tiempo y en la historia humana, encarnándose en una mujer. En la Virgen de la Escala quedarían sintetizadas o referidas de modo indirecto las «dos tiendas» (la generada por mano divina y la realizada por el hombre) citadas por san Pablo en su epístola a los Hebreos (Heb 8, 1-6) y que inspiran todo el programa iconográfico de la capilla, en palabras del propio Rupnik.

En esta imagen de la Virgen también los ropajes adquieren significado, pues Cristo, revestido con estola, se muestra ya en su infancia como sacerdote eterno, mientras los colores azul y rojo que tiñen el manto y la túnica de la Virgen revelan su maternidad divina y su humanidad, estableciendo un equilibrio cromático con el Pantocrátor. La utilización prioritaria de ambos colores en la paleta de Rupnik permite situarlo en la órbita de su admirado Kandinsky, quien ya había considerado que «el azul es el color típicamente celeste, que desarrolla profundamente el elemento de quietud (...) y el rojo da la sensación de fuerza, energía, impulso... $»{ }^{36}$ Como detalles, a priori ornamentales, tres pequeñas estrellas doradas destellan en el manto de la Virgen, siguiendo también

33 Ibídem: 57.

34 Únicamente el Pantocrátor realizado en la iglesia de San Lorenzo de Roma introduce una policromía diferente en las vestimentas, de color blanco como reflejo de la luz tabórica.

35 La tipología de la Virgen de la Escala ya había sido introducida por el Centro Aletti en la iglesia eslovena de san Juan Bautista (Ljubljana, 2002), aunque en este caso destaca la posición orante del Niño, no revestido de ropajes sacerdotales y desprovisto de atributos iconográficos. Asimismo en el ejemplo esloveno se acentúa la expresión melancólica de la Virgen, haciéndose esta incluso extensible a la figura de Cristo.

36 Kandinsky 1996: 74 y 79. 
FIGURA 6

Virgen de la Escala (detalle del ábside de la capilla del Colegio Mayor San Pablo). (Fotografía: David Monreal)

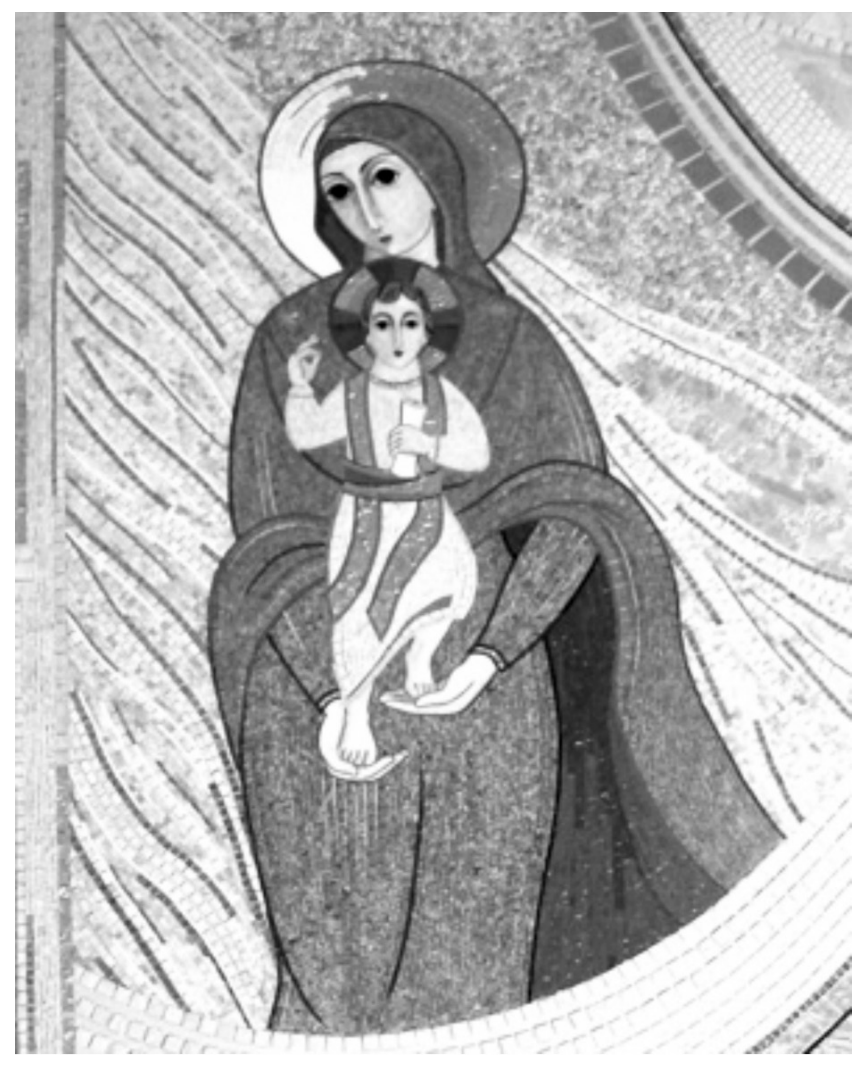

en estos motivos la tradición bizantina, posteriormente retomada en el Trecento italiano. La disposición triangular de estas estrellas, casi imperceptibles en la contemplación del conjunto, introduce un significado trinitario ya que el Hijo, generado por el Padre, entra en la historia humana "por obra y gracia del Espíritu Santo». ${ }^{37}$ Completando el simbolismo de los colores en la Virgen de la Escala, cabe reseñar que el nimbo de la Virgen no es dorado en su totalidad, como cabría esperar, sino que presenta una parte blanca, de aspecto inacabado. En realidad, en los mosaicos del Centro Aletti, el blanco es el color de la luz tabórica, de la luz de la revelación, lo que implica una especial dignidad para la figura que lo porta. ${ }^{38}$

Los gestos también son significativos en la transmisión de conceptos, pues mientras el Niño porta con una de sus manos un rollo de pergamino, aludiendo a la Nueva Ley, con su mano derecha repite el mismo gesto de bendición que el Pantocrátor superior, lo que de nuevo subraya la unidad compositiva del programa iconográfico. ${ }^{39}$ Sin embargo, a diferencia del hieratismo del Pantocrátor, el rostro de María está envuelto en un halo de tristeza, recordando la incipiente humanización de los iconos bizantinos que mostraban a la Eleusa o Virgen de la ternura meditando sobre el destino de su $\mathrm{Hijo}^{40}$, expresión que aquí adquiere sentido pleno al con-

\footnotetext{
37 Rupnik 2009b: 10.

38 Portal 1996: 25.

39 Respecto al carácter conceptual de los gestos, fundamental en el arte paleocristiano y de la Edad Media, Garnier 1989.

40 Uno de los ejemplos más conocidos del arte de la época de los Comnenos es la Virgen de la Ternura o Virgen Vladimir, datada en el siglo
}

templar la imagen inferior del Descendimiento. De hecho las líneas dibujadas por las teselas que rodean a la Virgen conducen nuestra mirada a esta escena final de la Pasión.

\section{La Renovación de iconográfica del Centro Aletti en la ESCENA DEL DESCENDIMIENTO DE CRISTO}

En la iconografía medieval lo habitual era vincular la escena del Descendimiento a la de la Crucifixión, pero Rupnik le otorga un protagonismo absoluto, destacando la asimetría en su tratamiento, la introducción de los personajes secundarios y el color con carácter simbólico. Es la representación de mayor expresividad del ábside (Figura 1) y, podríamos decir, que la que más se acerca al lenguaje fauvista de Matisse, por la desproporción de los personajes, el desequilibrio en su disposición y su aparente simplicidad formal. José de Arimatea y Cristo se presentan prácticamente fundidos en la misma figura, quedando ambos diferenciados por el contraste entre la túnica y el manto de José y el blanco sudario de Cristo. ${ }^{41}$ José desclava el brazo derecho de Cristo pero, a diferencia de las imágenes de la tradición, no porta las tenazas, que se habían convertido en símbolo parlante de esta escena, sino que extrae directamente el clavo, simplificando al máximo los elementos sin menoscabo de la expresividad.

Otra de las innovaciones de Rupnik la encontramos a los pies de la escena, con la presencia de María Magdalena secando los pies de Cristo con su propio cabello, gesto de arrepentimiento y conversión, propio de la unción de Betania y no del instante representado. El anacronismo de la figura llama nuestra atención sobre las llagas de los pies, enmarcadas por sus cabellos, de modo que se pone de manifiesto como mediante la sangre de Cristo se reconcilian las "cosas del cielo y de la tierra», tal como señalaba el libro del Pantocrátor recogiendo un versículo de Colosenses (Col 1, 20). La figura de la mujer, trabajada con líneas y formas curvas revela la incidencia del Matisse más tardío de la Capilla de Vence, donde domina la simplificación de las formas a partir de marcados contornos y amplios campos de colores puros. ${ }^{42}$ Rupnik se acerca al Matisse que describe la obra de sus últimos años como abstracción con arraigo en la realidad. En esta escena se pone de manifiesto cómo Rupnik de nuevo prescinde de cualquier escenografía que pueda desviar la atención de las figuras, reducidas aquí respecto a otras interpretaciones del tema, donde Rupnik también introduce a la Virgen. ${ }^{43}$ Como contrapunto de los

XII (Galería Tretiakov, Moscú). La aflicción de la Madre obedece a la conciencia de que «una espada atravesará tu alma para que se descubran los pensamientos de muchos corazones» (LC 2, 35). Zibawi 1999: 146.

41 La unidad de ambos rostros parece inspirada en la representación que el Centro Aletti realiza del Descendimiento en el Via Crucis de Mengore (Eslovenia, mayo 2008) y anticipa la del Via Crucis de la iglesia de la Exaltación de la Santa Cruz (Serbia, septiembre 2013).

42 Rodríguez Velasco 2009: 11.

43 En algunos ejemplos opta por la representación de la Piedad, como puede observarse en la Sala Capitular de la Catedral de la Almudena (Madrid, octubre 2006) y en la Catedral de la Madre de Dios (Castanhal, Brasil, diciembre de 2014). En los otros conjuntos donde introduce el Descendimiento, a los personajes de José de Arimatea y de María Magdalena suma la presencia de la Virgen, como en la Capilla de las Hermanas Hospitalarias del Sagrado Corazón (Roma, junio 2001) y el Santuario de la Virgen de la Salud (Scaldaferro, Italia, marzo 2006). 
personajes, cerrando la lectura iconográfica del ábside, una cruz que hace evidente el simbolismo del color, pues el negro refiere la muerte, dejando paso al blanco y al dorado para referir la futura resurrección. En el tratamiento de los materiales, Rupnik ha querido evocar con la cruz los tejados de pizarra del colegio mayor, algo propio de sus intervenciones, donde a menudo introduce materiales locales para establecer un mayor arraigo entre el mosaico y el lugar donde es realizado.

LA OBRA DE ARTE COMO TOTALIDAD: ICONOGRAFÍA Y SIGNIFICADO DE LA CRUZ PROCESIONAL Y EL LAMPADARIO

Inspiración patrística en la imagen de Cristo como «nuevo Adán»

En la capilla del Colegio Mayor San Pablo, completando los mosaicos se alza una cruz de bronce dorado (Figura 7), que repite el modelo de aquella que preside la pequeña capilla del Centro Aletti (Roma, 2003). ${ }^{44}$ Al tratarse de una pieza procesional, su iconografía parece simplificarse respecto a los mosaicos que recreaban la crucifixión, donde a menudo se representaban los personajes secundarios de la tradición medieval, como Longinos y Stephaton. Desde su primera imagen en mosaico de la Crucifixión, en la Capilla Redemptoris Mater (Palacio Apostólico Vaticano, 19961999), Rupnik incluye a la Virgen junto a Longinos para expresar de forma alegórica el nacimiento de la Iglesia. ${ }^{45}$

El primer rasgo digno de reseñar en la cruz procesional es la estructura a modo de "árbol de la vida», lo que imprime gran dinamismo compositivo y sobre todo una riqueza simbólica heredada de la tradición medieval. Ya entonces la sustitución de los maderos por troncos con las ramas taladas, sintetizaba la unidad de Antiguo y Nuevo Testamento, recordando los escritos patrísticos que trazaban la analogía entre el madero que nos llevó a la muerte y el que nos llevó a la salvación. Así lo refiere Cesaréo de Arlés (h. 470-542) en uno de sus sermones: "Adán ha mostrado el árbol de la muerte y Jesús el árbol de la vida». ${ }^{46}$ En la

44 Esta cruz es realizada también en la capilla de la Universidad del Sagrado Corazón de Connecticut (agosto 2008), en la iglesia de San Giovanni Rotondo (San Pio de Pietrelcina, junio de 2009), en la capilla del Colegio Pontificio Irlandés (Roma, febrero de 2010), en la capilla de la Maison Marie Saint Freu (Tarbes, Francia, mayo de 2012) y en la capilla de la Casa de la Salud (Belas, Portugal, mayo de 2013).

${ }^{45}$ El protagonismo de Longinos se repite años más tarde en el programa decorativo de la iglesia de San Marcos (Koper, Eslovenia, agosto de 2003). La presencia de la Virgen es más frecuente, como se observa en los siguientes conjuntos: Capilla del Seminario de Banska Bystrica (Badin, Eslovaquia, junio de 2003), en la capilla de la Sagrada Familia (New Haven, Connecticut, febrero de 2005), la iglesia de santa Clara, del Pontificio Colegio francés (Roma, 2004), la Casa de los Encuentros Cristianos (Capiago, febrero de 2006), la capilla de las Hijas de la Misericordia de la Tercera Orden de san Francisco (Roma, febrero de 2007), la parroquia de María Inmaculada (Modugno, Italia, mayo de 2007), la capilla del Policlínico Humberto I (Roma, junio de 2007), capilla del Corazón Misericordioso de Jesús (Vepric, Croacia, 2008), Capilla de la Casa Generalicia de los Marianistas (Roma, octubre de 2008), capiIla del hospital Beato Menni (Valladolid, mayo de 2010), iglesia de San Modesto (Kranj, Eslovenia, octubre de 2010), capilla de las Hermanas de Jesús Buen Pastor (Roma, noviembre de 2011), iglesia de Santa María Madre de la Iglesia (Zaragoza, diciembre de 2011), e iglesia de San Pedro (Gijón, mayo de 2012).

46 Cfr. Dulaey 2003: 265.
FIGURA 7

Cruz de bronce (detalle, capilla del Colegio Mayor San Pablo). (Fotografía: David Monreal)

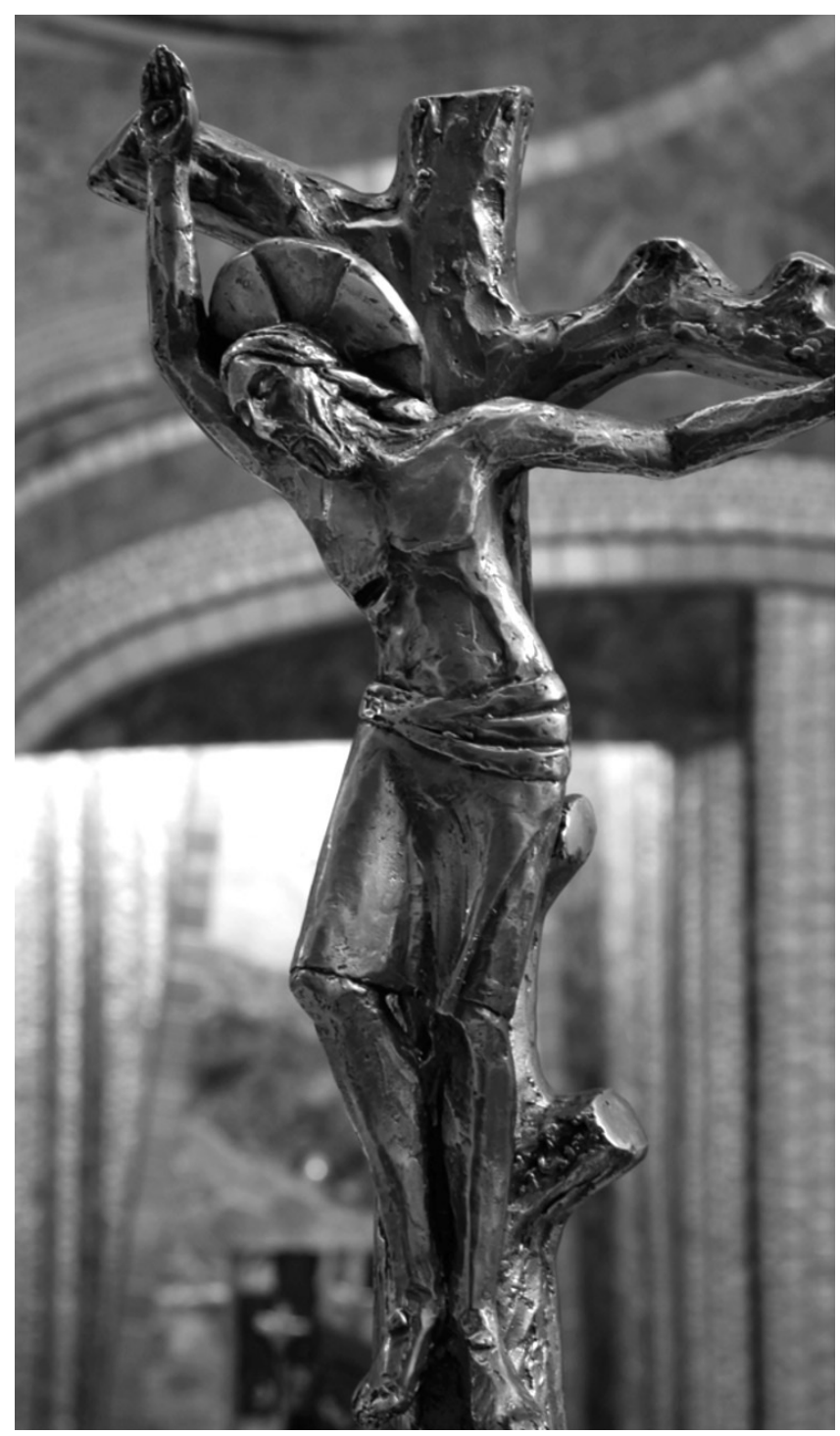

medida que la cruz presentada por Rupnik es conformada por el árbol de la ciencia, Cristo se presenta como «nuevo Adán», concordancia también subrayada por los textos patrísticos que afirman cómo las primeras gotas de la sangre de Cristo son derramadas sobre el enterramiento de Adán, exaltando así el valor redentor de la cruz sobre el pecado. San Ireneo sintetiza esta vinculación entre Adán y Cristo al afirmar: «como por el primer hombre todos habían sido encadenados a la muerte por el hecho de la desobediencia, era necesario que, por la obediencia de Aquel que se haría hombre por nosotros, fuéramos librados de la muerte». ${ }^{47}$

En esta pieza la mayor novedad iconográfica la encontramos en los relieves del basamento, que de nuevo nos obligan a remontarnos a los programas decorativos bizantinos. A diferencia de los modelos medievales que presentaban a los pies de la cruz mascarones, sepulcros, esqueletos, huesos o calaveras para simbolizar la presencia del enterramiento de Adán, Rupnik renueva la iconografía

47 Ibídem: 258-259. 
FIGURA 8

Cruz de bronce (detalle de Anástasis, capilla del Colegio Mayor San Pablo). (Fotografía: David Monreal)

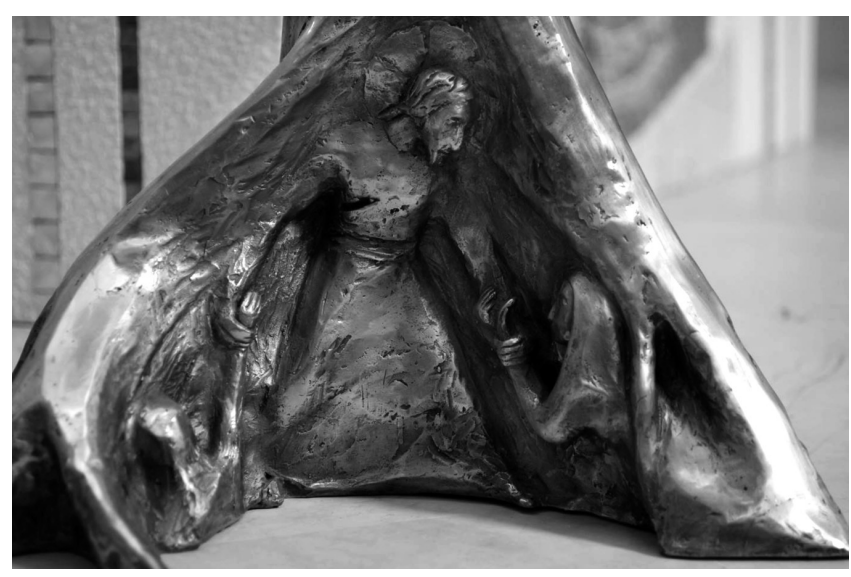

al introducir, con un modelado de formas deshechas, la Anástasis o Bajada de Cristo a los Infiernos (Figura 8). Mediante esta escena, casi imperceptible, se explicitan de nuevo las ideas sugeridas anteriormente, el valor redentor de la cruz y la figura de Cristo como «nuevo Adán». ${ }^{48}$

\section{El lampadario como expresión de la «lux nova»}

La luz también es fundamental en los conjuntos del Centro Aletti, por lo que, desde que reciben un encargo, lo primero que realizan es un estudio de la arquitectura donde van a intervenir, especialmente en lo que se refiere a la disposición de las entrada del luz. Esto obedece a que la luz, en su incidencia más o menos directa sobre las teselas, exalta la materia creando un juego de brillos y reflejos que potencia la capacidad expresiva de los mosaicos. Al igual que para los arquitectos medievales, para Rupnik la luz es más que una realidad física y se reviste de sentido trascendente. Esto se observa, por ejemplo, en la remodelación de esta capilla, un espacio más oscuro en su estructura anterior y que a partir de su remodelación arquitectónica privilegia la incidencia de la luz natural en el sagrario. Con estas consideraciones los artistas del Centro Aletti se hacen eco del simbolismo que la luz había tenido en la configuración espacial del Medievo, especialmente en la construcción de las catedrales, donde la apertura de grandes claristorios coloreados favorecía una luz de fuerte sentido alegórico y trascendente. ${ }^{49}$ Podemos decir que en los mosaicos de Rupnik se advierte la huella del pensamiento estético medieval respecto a la luz, considerada condición para la belleza, como se desprende de la filosofía tomista que definía

48 Esta unidad entre Crucifixión y Anástasis se da de forma narrativa en otros conjuntos del Centro Aletti, como la Sacristía de la Catedral de la Almudena (Madrid, septiembre de 2005), Rupnik y Cervera Barranco 2008.

La combinación de Crucifixión y Anástasis la encontramos entre los manuscritos del románico hispano en las escenas que ilustran el Nuevo Testamento de la Biblia de Ávila, manuscrito de origen italiano pero completado en su decoración en España en torno al último cuarto del siglo XII. Rodríguez Velasco 2010: 541-558.

49 Respecto al valor trascendente de la luz en las catedrales góticas, Nieto Alcaide 1989: 55. lo bello como "consonancia de las partes y luminosidad», o de los planteamientos de san Buenaventura al considerar que «la luz basta para explicar la belleza». ${ }^{50}$ En definitiva, las obras del Centro Aletti parecen proponer de nuevo la «lux nova» que el abad Suger impulsó en su renovación de la abadía de Saint Denis. ${ }^{51}$

En la capilla del Colegio Mayor el protagonismo de la luz se ve reforzado por un gran lampadario (Figura 9), pieza que evidencia la concepción de "obra de arte total» con que Rupnik aborda sus conjuntos, trabajando hasta el mínimo detalle. ${ }^{52}$ Esta creación, a modo de gran corona de luces, se dispone sobre el altar de la capilla, acentuando la centralización de la planta y el protagonismo de la cúpula. Su forma ya implica simbolismo, teniendo en cuenta que el círculo es considerado signo de la perfección de Dios, por no tener principio ni fin, al tiempo que recuerda la concepción eterna de la Iglesia, a lo que Rupnik añade nuevos significados. En primer lugar este monumental candelabro hace presente la luz de Cristo sobre la comunidad, por lo que en su estructura se suceden pequeñísimos puntos de luz que deben permanecer siempre encendidos para hacer patente que entramos «en un ámbito donde la luz no se pone ya, donde no hay oriente ni occidente, aurora u ocaso".$^{53}$ En segundo lugar, la presencia de ocho cruces jalonando el armazón circular simboliza la luz del octavo día, la luz increada derramada por el Espíritu Santo, la luz sin ocaso. En este sentido, se hace de nuevo presente la tradición patrística, pues ya Orígenes, en el siglo III, hablaba del octavo día como expresión de plenitud, señalando que «el número ocho, que contiene la virtud de la resurrección, es figura del mundo futuro». ${ }^{54}$

FIGURA 9

\section{Lampadario (capilla del Colegio Mayor San Pablo). (Fotografía: David Monreal)}

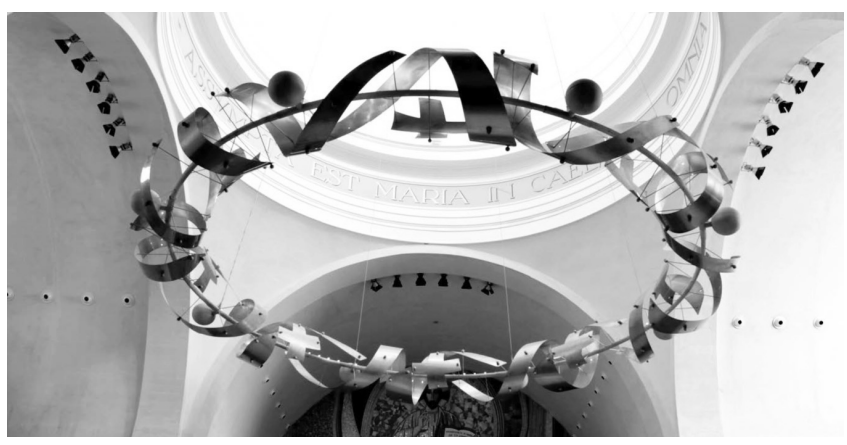

50 Cfr. Bruyne 1987: 147

51 Panofsky 2004: 38-39.

52 Esta consideración de "obra de arte total», trabajando hasta el mínimo detalle, nos lleva a establecer un paralelismo con Antonio Gaudí, que abordaba sus empresas arquitectónicas con este mismo espíritu. También en este caso se podría establecer un parangón con el baldaquino-lampadario que Gaudí realiza en la remodelación del presbiterio de la catedral de Palma de Mallorca, inspirándose en la esencia gótica de dicha catedral.

53 Rehabilitación de la Capilla del Colegio Mayor San Pablo. Renovación y adaptación litúrgica por el P. Marko Iván Rupnik, Director del Centro Aletti (Pontificio Instituto Oriental, Roma).

${ }^{54}$ Cfr. Campatelli 2007: 165. 


\section{CONCLUSIONES}

Los mosaicos del Centro Ezio Aletti evidencian la renovación del arte sacro contemporáneo sin renunciar a la tradición de las imágenes paleocristianas y medievales y a los textos que inspiran sus significados. Ahondando en el programa iconográfico de la capilla del Colegio Mayor San Pablo se aprecia la figura de Rupnik como artista del color y la materia, en la línea de las propuestas vanguardistas, consciente de que su obra se dirige al hombre del siglo XXI. Observamos que la creación de este monumental mosaico está en relación directa con la estructura arquitectónica, con la advocación del edificio y, sobre todo con la finalidad litúrgica del mismo, más allá de los debates entre figuración o abstracción, rechazados por Rupnik por desviarnos del sentido último de la creación artística. Los mosaicos del Centro Aletti, como se observa en este conjunto madrileño, provocan en el espectador continuos interrogantes que encuentran su respuesta en el conocimiento artístico y teológico de la tradición, reinterpretados a partir de un profundo conocimiento del arte contemporáneo y de la teología rusa del siglo XIX. De este modo, la riqueza de estos mosaicos estriba también en su capacidad de sintetizar tradición oriental y occidental en total unidad y consonancia de significados. El propio Rupnik define la obra de su taller como «un arte de síntesis profunda donde las tradiciones pueden reflorecer como alimentos para la creación artística de hoy y el arte contemporáneo permita que los tesoros escondidos, aparentemente sellados en el pasado, reaparezcan con su savia vital $\gg{ }^{55}$ Para ello, como se aprecia en la capilla del Colegio Mayor es esencial la concepción del símbolo capaz de desvelar, en palabras del propio artista, «una visión unitaria del mundo. Esto es lo que ha llevado a los cristianos a desarrollar las grandes épocas del arte, como el bizantino o el románico, donde todo se ha basado en esta visión unitaria del símbolo». ${ }^{56}$

\section{BiBLIOGRAFÍA}

Arriola Jiménez, M. 2013. «La obra inicial de Marko Iván Rupnik y su vinculación al arte contemporáneo» en M. Rodríguez Velasco (coord.): Tradición y modernidad en la obra de Marko Iván Rupnik. Implicaciones teológicas, estéticas e iconográficas de los mosaicos del Centro Ezio Aletti (Roma): 17-77. Madrid: CEU Ediciones.

Belting, H. 2009. Imagen y culto. Una historia de la imagen anterior a la edad del arte. Madrid: Akal.

Bruyne, E. de. 1987. La estética de la Edad Media. Madrid: Balsa de la Medusa.

Campatelli, M. 2007. Il Battesimo. Ogni giorno alle fonti della vita nuova. Roma: Lipa.

Dölger, F. J. 2013. Paganos y Cristianos. El debate de la Antigüedad sobre el significado de los símbolos. Madrid: Encuentro.

Dulaey, M. 2003. Bosques de símbolos. La iniciación cristiana y la Biblia (siglos I-IV). Madrid: Ediciones Cristiandad.

Garnier, F. 1989. Le langage de l'image au Moyen Age. Grammaire des gestes. París: Le Léopard d'Or.
Govekar, N. y Rupnik, M. I. 2013. El rojo de la plaza de oro. Burgos: Monte Carmelo.

Grabar, A. 2007. Los orígenes de la estética medieval. Madrid, Siruela. Kandinsky, V. 1996. De lo espiritual en el arte. Barcelona: Paidós.

Krautheimer, R. 1981. Arquitectura paleocristiana y bizantina. Madrid: Cátedra.

Lynch, J. 2011. "Il serpente». Fraternitá e Missione 4: 7.

Malaxecheverría, I. 1991. Fauna fantástica de la Península Ibérica. San Sebastián: Kriselv.

Mâle, E. 2001. El arte religioso del siglo xIII en Francia. Madrid: Encuentro.

Mancinelli, F. 1981. Catacumbas de Roma. Origen del cristianismo. Florencia: Scala.

Nieto Alcaide, V. 1989. La luz, símbolo y sistema visual. Madrid: Cátedra.

Panofsky, E. 2004. El abad Suger: sobre la abadía de Saint Denis y sus tesoros artísticos. Madrid: Cátedra.

Plazaola, J. 1996. Historia y sentido del arte cristiano. Madrid: Biblioteca de Autores Cristianos.

Portal, F. 1996. El simbolismo de los colores: en la antigüedad, la Edad Media y los tiempos modernos. Palma de Mallorca: Olañeta.

Rodríguez Velasco, M. 2009. "Iconografía, imagen y estética en los mosaicos de Marko Ivan Rupnik: una mirada desde la tradición». Debate Actual 13: 8-35.

Rodríguez Velasco, M. 2010. «Iconografía de Prendimiento, Crucifixión y Descendimiento de Cristo en la miniatura románica: el programa decorativo del folio CCCXXIIII r de la Biblia de Ávila», en J. Campos (ed.), Los Crucificados: religiosidad, cofradías y arte: 541-558. Madrid: Instituto Escurialense de Investigaciones Históricas y Artísticas.

Rodríguez Velasco, M. 2012. «Tradición y modernidad: Iconografía de la Anunciación en los mosaicos del Centro Ezio Aletti (Roma)», en J. Campos (ed.), Advocaciones marianas de Gloria: 1063-1082. Madrid: Instituto Escurialense de Investigaciones Históricas y Artísticas.

Rodríguez Velasco, M. 2013. «Tradición y modernidad en los programas iconográficos del Centro Aletti (Roma): Una reinterpretación de modelos paleocristianos, bizantinos, románicos y góticos con el lenguaje del arte contemporáneo», en M. Rodríguez Velasco (ed.), Tradición y modernidad en la obra de M. I. Rupnik: Implicaciones teológicas, estéticas e iconográficas de los mosaicos del Centro Ezio Aletti (Roma): 79-139. Madrid: CEU Ediciones.

Rupnik, M. I. 2000. Decir el hombre. Icono del Creador, revelación del amor. Madrid: PPC.

Rupnik, M. I. 2003. Los colores de la luz. Burgos: Monte Carmelo.

Rupnik, M. I. y Cervera Barranco, P. 2008. La Catedral de la Almudena. Mosaicos de la Sacristía Mayor y la Sala Capitular. Burgos: Monte Carmelo.

Rupnik, M. I. 2009a. «Implicaciones teológicas del mosaico: tradición y modernidad», en J. Prades (ed.): Dios es amor: 61-71. Madrid: San Dámaso.

Rupnik, M. I. 2009b. Mosaici della Madre di Dio. Roma: Lipa.

Rupnik, M. I. 2011. "Il pelicano». Fraternitá e Missione 4: 9.

Sánchez López, J. A. 1991. "Iconografía e iconología del pelícano: un ensayo sobre la reconversión del concepto de filantropía». Boletín de Arte 12: 127-146.

Spidlík, T. y Rupnik, M. I. 2003. La fe según los iconos. Burgos: Monte Carmelo.

Spidlík, T. 2004. Miscellanea I. Alle fonti dell'Europa. Roma: Lipa.

Spidlík, T. y Rupnik, M. I. 2013. El conocimiento integral. La vía del símbolo. Madrid: BAC.

VV. AA. 2002. La Capilla "Redemptoris Mater» del Papa Juan Pablo II. Burgos: Monte Carmelo.

VV. AA. 2012. Iconografía y Arte Cristiano. Madrid: San Pablo.

Zibawi, M. 1999. Iconos. Sentido e Historia. Madrid: Libsa.

\footnotetext{
55 Cfr. VV. AA., La Capilla Redemptoris Mater... p. 179.

56 Govekar y Rupnik 2013: 91.
} 